\title{
Product Form Design Model Based on Multiobjective Optimization and Multicriteria Decision-Making
}

\author{
Meng-Dar Shieh, ${ }^{1}$ Yongfeng Li, ${ }^{1}$ and Chih-Chieh Yang ${ }^{2}$ \\ ${ }^{1}$ Department of Industrial Design, National Cheng Kung University, No. 1 University Road, Tainan 70101, Taiwan \\ ${ }^{2}$ Department of Multimedia and Entertainment Science, Southern Taiwan University of Science and Technology, \\ No. 1 Nantai Street, Yungkang District, Tainan 71005, Taiwan
}

Correspondence should be addressed to Yongfeng Li; yflidr@hotmail.com

Received 18 July 2016; Accepted 28 November 2016; Published 11 January 2017

Academic Editor: Thomas Hanne

Copyright (C) 2017 Meng-Dar Shieh et al. This is an open access article distributed under the Creative Commons Attribution License, which permits unrestricted use, distribution, and reproduction in any medium, provided the original work is properly cited.

\begin{abstract}
Affective responses concern customers' affective needs and have received increasing attention in consumer-focused research. To design a product that appeals to consumers, designers should consider multiple affective responses (MARs). Designing products capable of satisfying MARs falls into the category of multiobjective optimization (MOO). However, when exploring optimal product form design, most relevant studies have transformed multiple objectives into a single objective, which limits their usefulness to designers and consumers. To optimize product form design for MARs, this paper proposes an integrated model based on MOO and multicriteria decision-making (MCDM). First, design analysis is applied to identify design variables and MARs; quantification theory type I is then employed to build the relationship models between them; on the basis of these models, an MOO model for optimization of product form design is constructed. Next, we use nondominated sorting genetic algorithm-II (NSGA-II) as a multiobjective evolutionary algorithm (MOEA) to solve the MOO model and thereby derive Pareto optimal solutions. Finally, we adopt the fuzzy analytic hierarchy process (FAHP) to obtain the optimal design from the Pareto solutions. A case study of car form design is conducted to demonstrate the proposed approach. The results suggest that this approach is feasible and effective in obtaining optimal designs and can provide great insight for product form design.
\end{abstract}

\section{Introduction}

Because of the intense competition in contemporary markets, it is essential that companies produce products that meet the needs of consumers. Affective responses have attracted increasing attention as indicators of consumers' affective needs. Kansei engineering (also known as affective engineering) is a method for translating affective responses into design variables [1]. It has achieved considerable success in the field of product design $[2,3]$.

Affective responses to products have various aspects. Thus, the process of optimizing the form of a product capable of satisfying multiple affective responses (MARs) can be considered as a multiobjective optimization (MOO) problem, which is an important issue of Kansei engineering. Deriving an optimal product design is a complicated process in which several methods need to be combined. For example, Hsiao et al. [4] used quantification theory type I (QT1) to build the predictive models for MARs and then adopted analytical hierarchy process (AHP) to obtain the weights for MARs; on the basis of these weights, the values of the affective responses were integrated into a single objective value for product form optimization. Guo et al. [5] integrated the values of MARs, which were predicted using a back propagation neural network (BPNN) into a single objective value for design optimization by using a genetic algorithm (GA). These studies have addressed MARs; however, they transformed the MOO problem into a single objective optimization (SOO) problem in which only one solution is provided in each simulation run. This approach, which has the advantage of simplicity, can be considered a classical MOO [6]. However, it always requires advance preference information prior to optimization in circumstances with no knowledge of the possible consequences; furthermore, it precludes the consideration of 
all possible solutions, which provides the decision-makers with no alternative options because only one optimal solution is obtained after optimization. Thus, the classical MOO approach is of limited usefulness to designers and consumers.

In recent years, it has been recognized that $\mathrm{MOO}$ and multicriteria decision-making (MCDM) are mutually enhancing; considerable attention has been focused on combining MOO with MCDM to assist decision-makers in solving problems in real-world applications [7-9]. One essential approach for combining MOO with MCDM is the use of MOO to derive numerous Pareto solutions and then apply MCDM to select the best solution from the Pareto set [10]. This approach does not require advance information related to the preferences of the decision-maker. Moreover, it can provide a number of Pareto solutions in a single run in the form of a set of nondominated solutions rather than a single best solution. On the basis of these Pareto solutions, the decision-maker can make a trade-off decision. Therefore, this approach is more appropriate for addressing multiple objectives simultaneously [11] and tends to be more practical and less subjective [6].

Recently, several researchers in the product design field have investigated the application of MOO for obtaining Pareto optimal solutions. For example, Yang [12] used support vector regression (SVR) and nondominated sorting genetic algorithm-II (NSGA-II) in the construction of a hybrid Kansei engineering system (KES) for product form design. Jiang et al. [13] proposed a chaos-based NSGA-II for solving an MOO model in product design. However, these studies have focused mainly on obtaining Pareto solutions, not on further combining MCDM methods to find optimal design solution according to the consumers' preference. Few studies have investigated using a combined MOO-MCDM approach to realize optimal product form design.

This paper proposes a new design model which combines MOO with MCDM for addressing the problem of optimizing product form design. We employ NSGA-II as an MOO algorithm to generate Pareto optimal solutions. The fuzzy analytic hierarchy process (FAHP) is then adopted as the MCDM method to derive the optimal product form design. The rest of this paper is organized as follows: Section 2 briefly reviews the research context. Section 3 presents our proposed methodology. Section 4 demonstrates a case study with the proposed method, the results of which are discussed in Section 5. Finally, the conclusion is presented in Section 6.

\section{Literature Review}

2.1. Kansei Engineering System. Kansei engineering was founded at Hiroshima University about 30 years ago [14]. It focuses on the implementation of the consumer's affective response into product design. The Kansei implies the consumer's psychological feeling as well as embracing physiological issues. Kansei engineering is defined as translating the consumer's Kansei into design. The KES means a computer assisted design system of Kansei engineering which is usually based on artificial intelligence technology [15]. It can be used to meet the needs of consumers and facilitate more efficient product development. When implementing KES studies, the products are usually decomposed into design variables [16, 17]. The design variables can be discrete variables such as the type of design components $[18,19]$ and can also be continuous variables such as the coordinates of the feature points on the contour $[20,21]$. The result of KES study can provide deep insight for design.

Obtaining optimal designs that satisfy various consumers' affective responses, which falls into the category of MOO, has been a crucial subject in KES studies. Essentially, two approaches to solving MOO problems can be applied. One is the classical MOO method that converts multiple objectives into a single objective. This approach has been extensively used in KES $[4,5,22]$ and begins with the determination of a preference weight vector for use in the construction of a composite fitness function. Using this approach to obtain the most favourable product design is simple but somewhat subjective [6]. The other approach that involves combining MOO with MCDM has been used in engineering in recent years $[8,9,23]$. However, few studies have investigated using KES for product form design. The KES approach integrating $\mathrm{MOO}$ with MCDM does not require advance information on preferences and provides numerous Pareto solutions in a single run. Designers and consumers can evaluate the advantages and disadvantages of each of these Pareto solutions by using the MCDM method based on preference information and comparing them to derive the optimal product design.

These two approaches differ fundamentally with regard to the use of preference information. The classical MOO approach requires that the preference vector be supplied without any knowledge of the possible consequences. By contrast, combining MOO with MCDM uses preference information for selection of a single solution from the obtained Pareto set. Hence, this approach is more practical and less subjective. Therefore, the combined MOO-MCDM approach more effectively facilitates the product design process and is more appropriate to apply in KES. In this study, we apply this approach to KES for the purpose of obtaining optimal product form design.

2.2. Multiobjective Optimization. MOO addresses the multiple, often conflicting objectives that occur in real-world scenarios. An MOO problem can be formally defined as follows. Find the decision vector $x=\left[x_{1}^{*}, x_{2}^{*}, \ldots, x_{n}^{*}\right]^{T}$, which satisfies $m$ inequality constraints $g_{i}(x) \leq 0, \forall i=1,2, \ldots, m$ and $p$ equality constraints $h_{i}(x)=0, \forall i=1,2, \ldots, p$ and optimizes the vector of the objective function $f(x)=$ $\left[f_{1}(x), f_{2}(x), \ldots, f_{k}(x)\right]^{T}[24]$. It is not possible to optimize all $k$ objective functions that are in conflict with each other simultaneously by using one solution vector $x$. Therefore, a logical approach to MOO is to obtain a set of nondominated solutions which are known as Pareto optimal solutions. A solution $x \in \Omega$ is called "Pareto optimal" if and only if there is no $x^{\prime} \in \Omega$ for which $v=\left[f_{1}\left(x^{\prime}\right), f_{2}\left(x^{\prime}\right), \ldots, f_{k}\left(x^{\prime}\right)\right]^{T}$ dominates $u=\left[f_{1}(x), f_{2}(x), \ldots, f_{k}(x)\right]^{T}$. In other words, none of the solutions can be deemed better than the others in relation to all the objectives, and each ideally represents an optimal compromise between the objectives [25]. 


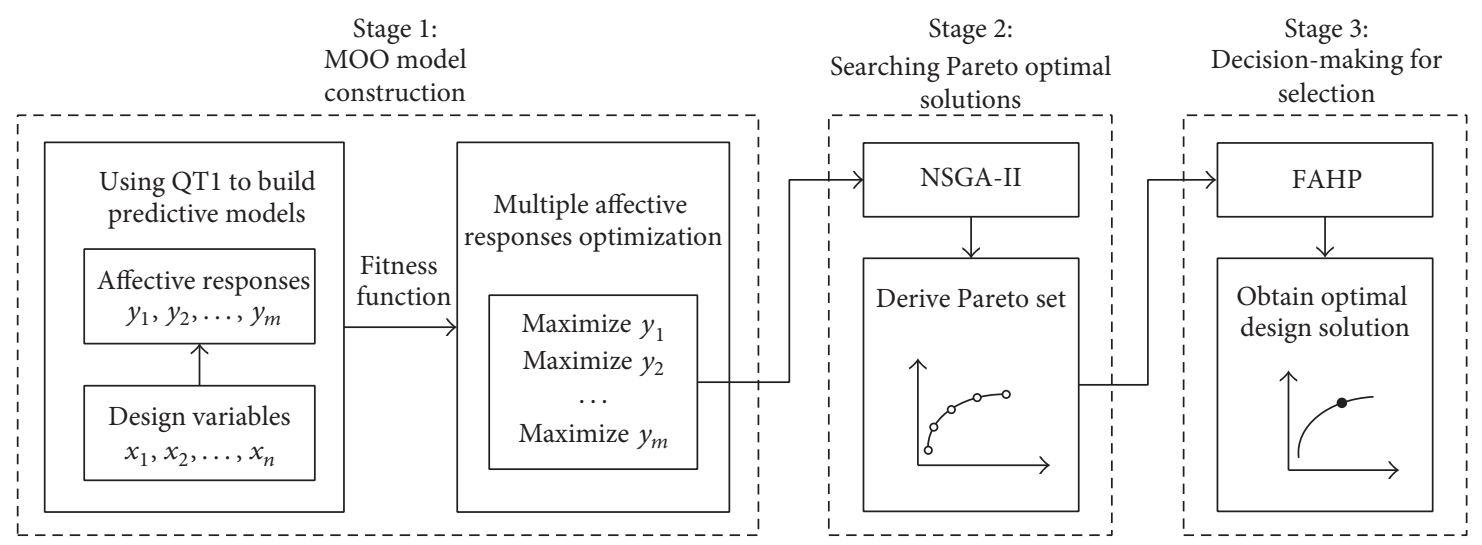

FIGURE 1: Framework of the proposed methodology.

Evolutionary algorithms are generic population-based metaheuristic optimization algorithms that mimic evolutionary principles. They are often used to solve optimization problems with multiple objectives, and are then called multiobjective evolutionary algorithms (MOEAs). MOEAs have the advantage of entailing no assumptions about the shape of Pareto fronts and being able to simultaneously search for a set of approximating Pareto fronts. Hence, they are recognized as powerful and versatile tools and have been used for solving MOO for over two decades. The nondominated sorting genetic algorithm (NSGA) proposed by Srinivas and Deb [26] is an essential type of MOEA. It has been relatively successful for several years. However, it is an inefficient algorithm mainly because of its method for classifying individuals. Deb et al. [27] proposed an improved version of NSGA, named NSGA-II. NSGA-II is currently the most commonly used MOO algorithm and has been used as a foundation for designing other algorithms. It has less time complexity and uses elitism and crowded comparison operator to ensure diversity that is very important to derive representative design solutions. Consequently, we adopt NSGA-II for Pareto set generation.

2.3. Multicriteria Decision-Making. MCDM is a discipline aimed at supporting decision-makers who are faced with numerous and conflicting alternatives in reaching an optimal decision [28]. MCDM has been successfully applied in practice and investigated by many researchers and scientists. The analytic hierarchy process (AHP) is an MCDM method that was originally developed by Saaty [29]. It is a structured qualitative and quantitative technique for addressing multiple criteria decision problems and has been successfully applied in many fields. However, when using AHP, the result of pairwise comparison must be expressed with crisp values, which does not conform to the fact that real-world judgement is subjective, uncertain, and fuzzy. van Laarhoven and Pedrycz [30] first added the fuzzy concept to AHP. Triangular fuzzy numbers were used to express judgements of the relative importance of two criteria. Because of insufficient use of the AHP method, Buckley [31] improved Saaty's traditional AHP and developed FAHP to incorporate fuzzy numbers into pairwise comparison. FAHP is very suitable for the user to express subjective preference related to affective responses. Therefore, we adopt FAHP as the MCDM method to derive the optimal design solution from the Pareto set.

\section{Proposed Methodology}

This paper proposes an integrated product form design model based on MOO and MCDM. To facilitate comprehension, assume that a consumer requires a product, such as a car, and has preferences that include "Modern," "Comfortable," "Rounded," and "Simple." Thus, the research question concerns how to derive an optimal car form design which corresponds to a specific consumer's preference weights for "Modern," "Comfortable," "Rounded," and "Simple." The proposed approach entails first obtaining many cars which satisfy Pareto optimality and then selecting the optimal car corresponding to the preference weights from these obtained cars.

Figure 1 shows the framework of the proposed methodology. QT1 is used to build the predictive models for affective responses. Based on these predictive models, an MOO model is constructed. NSGA-II is then used to search for the Pareto optimal design solutions. Subsequently, FAHP is employed to determine the optimal product form design solution.

3.1. Construction of Multiobjective Optimization Model. In the proposed methodology, design analysis that includes product form analysis and affective response analysis should first be conducted. Product form analysis can facilitate clarifying the character of the form for ascertaining the design variables. Our method uses morphological analysis, which can decompose a product into a set of design variables; optimal product form can then be identified by combining these design variables. The number of possible combinations is typically extremely high, and they entail not only existing and conventional solutions but also a wide range of variations and completely novel solutions [32]. To derive the experimental samples, we adopt orthogonal arrays that are a set of tables devised by Taguchi and are used to specify the minimum number of experiments needed. With regard to analysis of affective responses, Kansei words are adopted to describe people's responses to a product and factor analysis 
is then applied to identify the affective factors underlying these words. According to the affective response factors, the objectives for MOO and the criteria for making trade-off decision can be determined.

To construct the MOO model, it is necessary to first build models that use design variables to predict affective responses. In this study, QT1 is adopted, which has most often been used to build the predictive models for affective responses [1, 4]. QT1 is an extension of multiple linear regression analysis by using dummy coding. It can calculate nominal scaled explanatory variables and interval or proportionally scaled objective variables. Furthermore, it has the advantage of showing the contribution of each design variable for affective response quantitatively [33]. The degree of influence of each level of design variables on the affective responses is calculated as follows:

$$
\widehat{y}=\sum_{i=1}^{m} \sum_{j=1}^{n} \beta_{i j} x_{i j}+\varepsilon,
$$

where $\hat{y}$ is the affective response, $x_{i j}$ is the level of design variable, $\beta_{i j}$ is the weight for the level, $m$ is the number of design variables, $n$ is the number of levels, and $\varepsilon$ is the random variable.

The MOO problem in this study involves maximizing or minimizing all of the MRAs. For the maximization problem, the MOO model can be constructed as follows:

$$
\text { Maximize }\left[y_{1}, y_{2}, \ldots, y_{n}\right]^{T} \text {, }
$$

where $y_{i}(i=1,2, \ldots, n)$ is the affective response predicted using QT1.

3.2. Generation of Pareto Optimal Solutions by Using NSGA-II. The nondominated solutions can be obtained by solving the MOO model. Figure 2 illustrates the nondominated solutions for an optimization problem with two affective responses. The feasible area is inside (and the infeasible area is outside) the region surrounded by the curve. Each point in the feasible area represents a solution. The points located on the bold curve, which denotes the Pareto optimal frontier, are Pareto optimal solutions. Thus, the points $A, B, C, D, E$, and $F$ are the Pareto optimal solutions. Of any two such solutions, one is superior with respect to a specific affective response, but this superiority occurs only from sacrificing one of the other affective responses. Consequently, a decision-making process is necessary to determine which of them is the optimal product form design that most satisfies the affective needs of the consumer.

To generate the nondominated solutions, NSGA-II is adopted. Figure 3 shows the schematic of the NSGA-II algorithm [6]. This algorithm combines a parent population $P(t)$ of size $N$ and an offspring population $Q(t)$ of size $N$ to generate population $R(t)$ with a size $2 N$. The ranks of individuals in a population $R(t)$ are then calculated through nondominated sorting. Next, classify all individuals according to their ranks, and let $F_{i}$ be a subpopulation of individuals with the same rank. The next generation $P(t+1)$ is filled according to the order of the priority of these ranks,

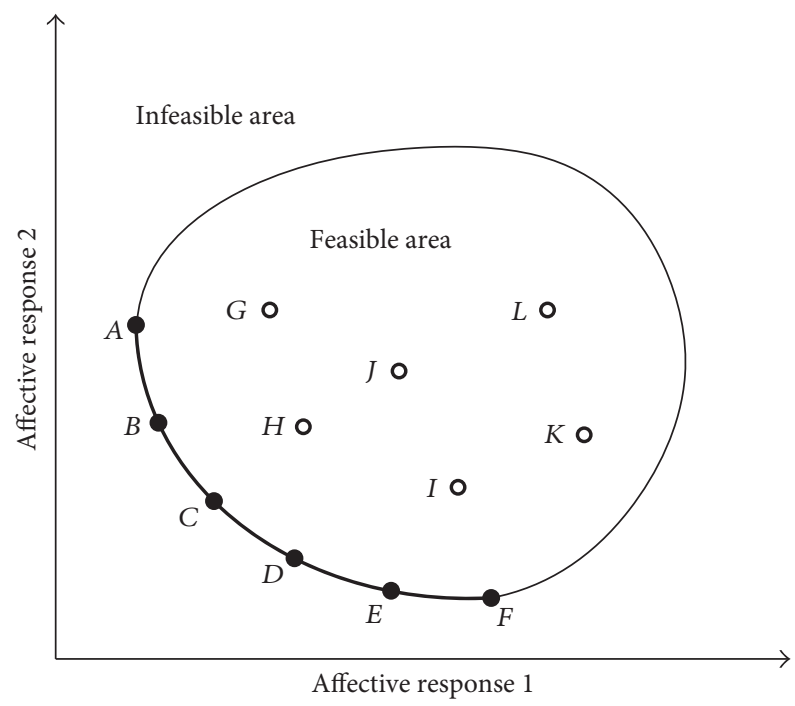

Figure 2: Schematic of the Pareto optimal solutions with two affective responses.

starting with the best nondomination ranks, followed by the second nondomination ranks and so on, until $P(t+1)$ is filled. Regarding the final rank, the solutions which have a larger crowding distance are prioritized for filling $P(t+1)$. Finally, the population of offspring population $Q(t+1)$ is generated from the parent population $P(t+1)$ by using tournament selection, crossover, and mutation. NSGA-II uses crowding distance to maintain diversity among nondominated individuals. Thus, it provides well-distributed individuals in the objective space, which is crucial for generating representative product design solutions.

3.3. Selection of Best Solution by Using FAHP. After obtaining Pareto optimal solutions, a decision-maker can use the MCDM method to determine which of the solutions is most suitable for the specific affective responses preference. In this research, FAHP is employed to determine the best design solution.

To represent subjective pairwise comparisons of customer requirements, triangular fuzzy numbers are used, which have the advantages of computational efficiency and ease of data acquisition. A triangular fuzzy number has the following membership function:

$$
\mu_{\widetilde{M}}(x)= \begin{cases}\frac{(x-a)}{(b-a)}, & a \leq x \leq b \\ \frac{(c-x)}{(c-b)}, & b \leq x \leq c \\ 0, & \text { otherwise }\end{cases}
$$

where $a$ and $c$ denote the lower and upper bounds of the fuzzy number $\widetilde{M}$, respectively, and $b$ denotes the modal value (Figure 4$)$. The triangular fuzzy number can be denoted by $\widetilde{M}=(a, b, c)$.

$\alpha$-cut is a means for converting a fuzzy set into a crisp set, which is very useful for defining the arithmetic operations 
TABLE 1: Linguistic terms, corresponding fuzzy number, and membership functions.

\begin{tabular}{lccccc}
\hline Linguistic terms & $\begin{array}{c}\text { Equally important } \\
(\text { EQI })\end{array}$ & $\begin{array}{c}\text { Moderately important } \\
(\mathrm{MI})\end{array}$ & $\begin{array}{c}\text { Strongly important } \\
(\text { SI) }\end{array}$ & $\begin{array}{c}\text { Very strongly important } \\
\text { (VSI) }\end{array}$ & $\begin{array}{c}\text { Extremely important } \\
\text { (EXI) }\end{array}$ \\
\hline Fuzzy numbers & $\widetilde{1}$ & $\widetilde{3}$ & $\widetilde{5}$ & $\widetilde{7}$ & $\widetilde{9}$ \\
Membership function & $(1,1,3)$ & $(1,3,5)$ & $(3,5,7)$ & $(5,7,9)$ & $(7,9,11)$ \\
\hline
\end{tabular}

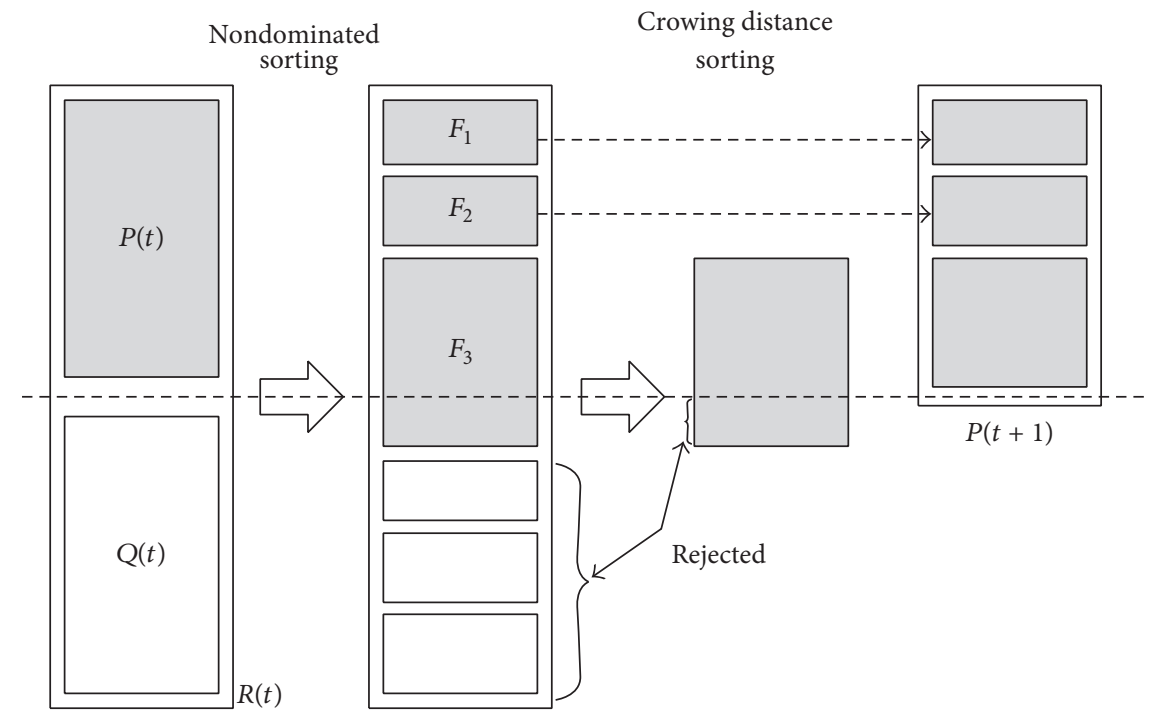

FIGURE 3: Schematic of NSGA-II.

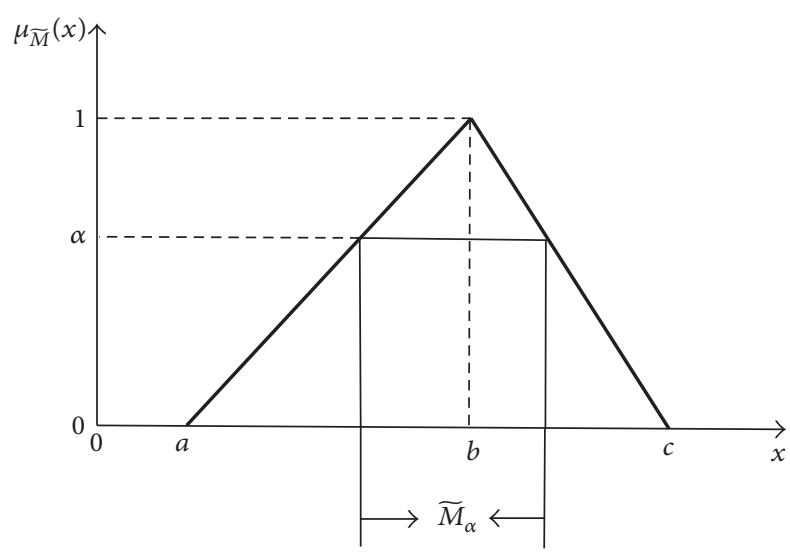

FIGURE 4: Illustration of $\alpha$-cut for triangular fuzzy number.

on fuzzy numbers [34]. The $\alpha$-cut of a fuzzy set $\widetilde{M}$ is a crisp set $\widetilde{M}_{\alpha}$ that contains all the elements that have a membership grade in fuzzy set $\widetilde{M}$ greater than or equal to the specified value of $\alpha$ (Figure 4). By defining the level of $\alpha$, the triangular fuzzy number can be characterised as

$$
\widetilde{M}_{\alpha}=\left[a^{\alpha}, c^{\alpha}\right]=[(b-a) \alpha+a,-(c-b) \alpha+c],
$$

$$
\forall \alpha \in[0,1] \text {. }
$$

To obtain the importance weights for multiple affective responses using FAHP has the following steps.

Step 1 (construct the fuzzy comparison matrix for MARs). Triangular fuzzy numbers $\widetilde{1}, \widetilde{3}, \widetilde{5}, \widetilde{7}$, and $\widetilde{9}$ indicate that criterion $i$ is of relative importance to criterion $j$ and then $\widetilde{1}^{-1}, \widetilde{3}^{-1}, \widetilde{5}^{-1}, \widetilde{7}^{-1}$, and $\widetilde{9}^{-1}$ indicate that criterion $j$ is of relative importance to $i$. The linguistic terms, corresponding fuzzy numbers, and membership functions are listed in Table 1, which were defined by Kwong and Bai [35].

The fuzzy pairwise comparison matrix for all the criteria is constructed as follows:

$$
\widetilde{A}=\left[\begin{array}{cccc}
1 & \tilde{a}_{12} & \cdots & \tilde{a}_{1 n} \\
\tilde{a}_{21} & 1 & \cdots & \widetilde{a}_{2 n} \\
\vdots & \vdots & \vdots & \vdots \\
\tilde{a}_{n 1} & \widetilde{a}_{n 2} & \cdots & 1
\end{array}\right]
$$

where

$$
\widetilde{a}_{i j}= \begin{cases}1, & i=j, \\ \widetilde{1}, \widetilde{3}, \widetilde{5}, \widetilde{7}, \widetilde{9}, \text { or } \widetilde{1}^{-1}, \widetilde{3}^{-1}, \widetilde{5}^{-1}, \widetilde{7}^{-1}, \widetilde{9}^{-1}, & i \neq j .\end{cases}
$$


TABLE 2: Table of random indexes.

\begin{tabular}{|c|c|c|c|c|c|c|c|c|c|c|c|c|c|c|c|}
\hline Order $N$ & 1 & 2 & 3 & 4 & 5 & 6 & 7 & 8 & 9 & 10 & 11 & 12 & 13 & 14 & 15 \\
\hline R.I. & 0 & 0 & 0.58 & 0.90 & 1.12 & 1.24 & 1.32 & 1.44 & 1.45 & 1.49 & 1.51 & 1.48 & 1.56 & 1.57 & 1.58 \\
\hline
\end{tabular}

Step 2 (determine the importance weight of MARs). The lower limit and upper limit of the fuzzy numbers with respect to $\alpha$ level can be defined as follows:

$$
\begin{aligned}
\tilde{1}_{\alpha} & =[1,3-2 \alpha], \\
\tilde{1}_{\alpha}^{-1} & =\left[\frac{1}{3-2 \alpha}, 1\right], \\
\tilde{3}_{\alpha} & =[1+2 \alpha, 5-2 \alpha], \\
\widetilde{3}_{\alpha}^{-1} & =\left[\frac{1}{5-2 \alpha}, \frac{1}{1+2 \alpha}\right], \\
\widetilde{5}_{\alpha} & =[3+2 \alpha, 7-2 \alpha], \\
\widetilde{5}_{\alpha}^{-1} & =\left[\frac{1}{7-2 \alpha}, \frac{1}{3+2 \alpha}\right], \\
\widetilde{7}_{\alpha} & =[5+2 \alpha, 9-2 \alpha], \\
\widetilde{7}_{\alpha}^{-1} & =\left[\frac{1}{9-2 \alpha}, \frac{1}{5+2 \alpha}\right], \\
\widetilde{9}_{\alpha} & =[7+2 \alpha, 11-2 \alpha], \\
\widetilde{9}_{\alpha}^{-1} & =\left[\frac{1}{11-2 \alpha}, \frac{1}{7+2 \alpha}\right] .
\end{aligned}
$$

Using the interval arithmetic and $\alpha$ cuts, $\tilde{a}_{i j}^{\alpha}$ can be expressed as follows:

$$
\tilde{a}_{i j}^{\alpha}=\left[a_{i j l}^{\alpha}, a_{i j u}^{\alpha}\right]
$$

$\alpha$ cuts of fuzzy matrix $\widetilde{A}$ can then be denoted as follows:

$$
\widetilde{A}_{\alpha}=\left[\begin{array}{ccc}
{\left[a_{11 l}^{\alpha}, a_{11 u}^{\alpha}\right]} & \ldots & {\left[a_{1 n l}^{\alpha}, a_{1 n u}^{\alpha}\right]} \\
\vdots & \ddots & \vdots \\
{\left[a_{n 1 l}^{\alpha}, a_{n 1 u}^{\alpha}\right]} & \ldots & {\left[a_{n n l}^{\alpha}, a_{n n u}^{\alpha}\right]}
\end{array}\right]
$$

The degree of satisfaction for the judgement matrix $\widetilde{A}_{\alpha}$ is estimated by the index of optimism $\mu$. A higher value of $\mu$ indicates a higher degree of optimism. In practical applications, $\mu=1, \mu=0.5$, and $\mu=0$ can be used to indicate that the decision-maker has an optimistic, moderate, or pessimistic view, respectively [36]. The index of optimism is a linear convex combination defined as [37]

$$
\widehat{a}_{i j}^{\alpha}=\mu a_{i j u}^{\alpha}+(1-\mu) a_{i j l}^{\alpha}, \quad \forall \mu \in[0,1]
$$

The following matrix can be obtained after setting the index of optimism $\mu$ :

$$
\widehat{A}=\left[\begin{array}{cccc}
1 & \widehat{a}_{12}^{\alpha} & \cdots & \widehat{a}_{1 n}^{\alpha} \\
\widehat{a}_{21}^{\alpha} & 1 & \cdots & \widehat{a}_{2 n}^{\alpha} \\
\vdots & \vdots & \ddots & \vdots \\
\hat{a}_{n 1}^{\alpha} & \hat{a}_{n 2}^{\alpha} & \cdots & 1
\end{array}\right] .
$$

The eigenvalues of matrix $\widehat{A}$ can be calculated by solving

$$
\operatorname{det}(\widehat{A}-\lambda I)=0 \text {. }
$$

The eigenvector $x$ with respect to the highest eigenvalue $\lambda_{\text {max }}$ can be calculated using

$$
\widehat{A} x=\lambda_{\max } x .
$$

The weighting vector $W=\left[w_{1}, w_{2}, \ldots, w_{n}\right]^{T}$ for the criteria can be determined after normalizing $x$.

Step 3 (verify the consistency of the evaluation). To ensure that the evaluations are consistent when the user conducts pairwise comparisons, a consistency index (C.I.) and consistency ratio (C.R.) are adopted. If C.I. and C.R. are both less than 0.1 , this indicates that the pairwise comparison is consistent [38]. The equations of C.I. and C.R. are as follows:

$$
\begin{aligned}
& \text { C.I. }=\frac{\lambda_{\max }-n}{n-1}, \\
& \text { C.R. }=\frac{\text { C.I. }}{\text { R.I. }}
\end{aligned}
$$

where $\lambda_{\max }$ is the highest eigenvalue of $\widehat{A}, n$ is the number of evaluation criteria, and R.I. refers to a random consistency index whose value increases if the number of criteria increases, as shown in Table 2 [29].

Step 4 (select the best design solution). The decision matrix $C$ for $n$ criteria and $m$ alternatives can be expressed as

$$
C=\left[\begin{array}{cccc}
c_{11} & c_{12} & \cdots & c_{1 n} \\
c_{21} & c_{22} & \cdots & c_{2 n} \\
\vdots & \vdots & c_{i j} & \vdots \\
c_{m 1} & c_{m 2} & \cdots & c_{m n}
\end{array}\right] .
$$

Thus, the performance value $v_{i}$ of the $i$ th design solution can be calculated as

$$
v_{i}=\sum_{j=1}^{n} c_{i j} w_{j}
$$

where $w_{j}$ denotes the normalized weight of the $j$ th criterion, which is calculated using FAHP. Finally, rank the design solutions according to the performance values. The solution ranking 1 st is the optimal design. 
TABLE 3: Design variables for cars' form.

\begin{tabular}{|c|c|c|c|c|}
\hline Design variables & Level 1 & Level 2 & Level 3 & \\
\hline $\begin{array}{l}X 1 \\
\text { (front bumper) }\end{array}$ & & & & $\left(x_{13}\right)$ \\
\hline $\begin{array}{l}X 2 \\
\text { (front part) }\end{array}$ & & & & $\left.x_{23}\right)$ \\
\hline $\begin{array}{l}X 3 \\
\text { (top part) }\end{array}$ & & & & $\left(x_{33}\right)$ \\
\hline $\begin{array}{l}X 4 \\
\text { (rear part) }\end{array}$ & & & & \\
\hline $\begin{array}{l}X 5 \\
\text { (rear bumper) }\end{array}$ & & & & $\left(x_{53}\right)$ \\
\hline
\end{tabular}

\section{Implementation Procedures}

\subsection{MOO Model Construction}

4.1.1. Design Analysis. A car is a representative example of a mature product. Car profile, which is a concentrated expression of the car form and provides a rich form language of car design, is receiving increasing emphasis in consumer car choice; considerable research has been conducted on this topic [18-21]. Therefore, this study adopts a car profile case to demonstrate the proposed method. A total of 120 profile images of cars currently on the market were collected. These images were reviewed by seven experts in the field of car design who used morphological analysis to construct the design variables that influence consumer feeling. These design variables can be divided into two categories: one is relevant to the form of different profile parts, as illustrated in Table 3; the other is relevant to the ratio of different profile parts, which also contributes greatly to the affective responses of product form [16], as shown in Table 4 . The design variables of $X 6, X 8$, and $X 12$ and the corresponding levels were adopted from Lai et al. [19].

The possible combinations of these design variables can generate $1,594,323\left(3^{13}=1,594,323\right)$ design solutions. To derive the experimental samples, Taguchi's $L_{27}\left(3^{13}\right)$ orthogonal array was adopted, and 27 combinative samples were obtained, as shown in Figure 5.
In Kansei engineering studies, Kansei words have been used to characterise the affective responses of consumers to products. A total of 258 affective descriptors were collected from car magazines and car company websites. From them, 20 pairwise Kansei words were selected as most relevant to car design. We employed factor analysis to investigate the factor structure of these words, wherein a minimum eigenvalue of 1 was adopted as the cutoff value. Table 5 lists the results of the factor analysis. The 20 pairwise Kansei words were grouped into four main factors, which account for $92.752 \%$ of the cumulative variance. When naming the factors, we employed pairwise Kansei words with maximum loading coefficients. Therefore, the four factors were named as "Traditional-Modern," "Uncomfortable-Comfortable," "Orthogonal-Rounded," and "Complex-Simple." On the basis of these factors, we can establish the objectives for MOO and also the criteria for MCDM.

4.1.2. Model Construction. To construct an MOO model, experimental data must first be obtained. A questionnaire was designed by combining the 27 representative samples with the four affective factors by using a 7-point semantic differential method (1-7), in which, for example, 1 is the most traditional and 7 is the most modern for the "TraditionalModern" Kansei word pair. We recruited 60 participants (30 females and 30 males, aged $22-30$ years) to fill out the questionnaire. The results are shown in Table 6. 
TABLE 4: Design variables for cars' ratio.

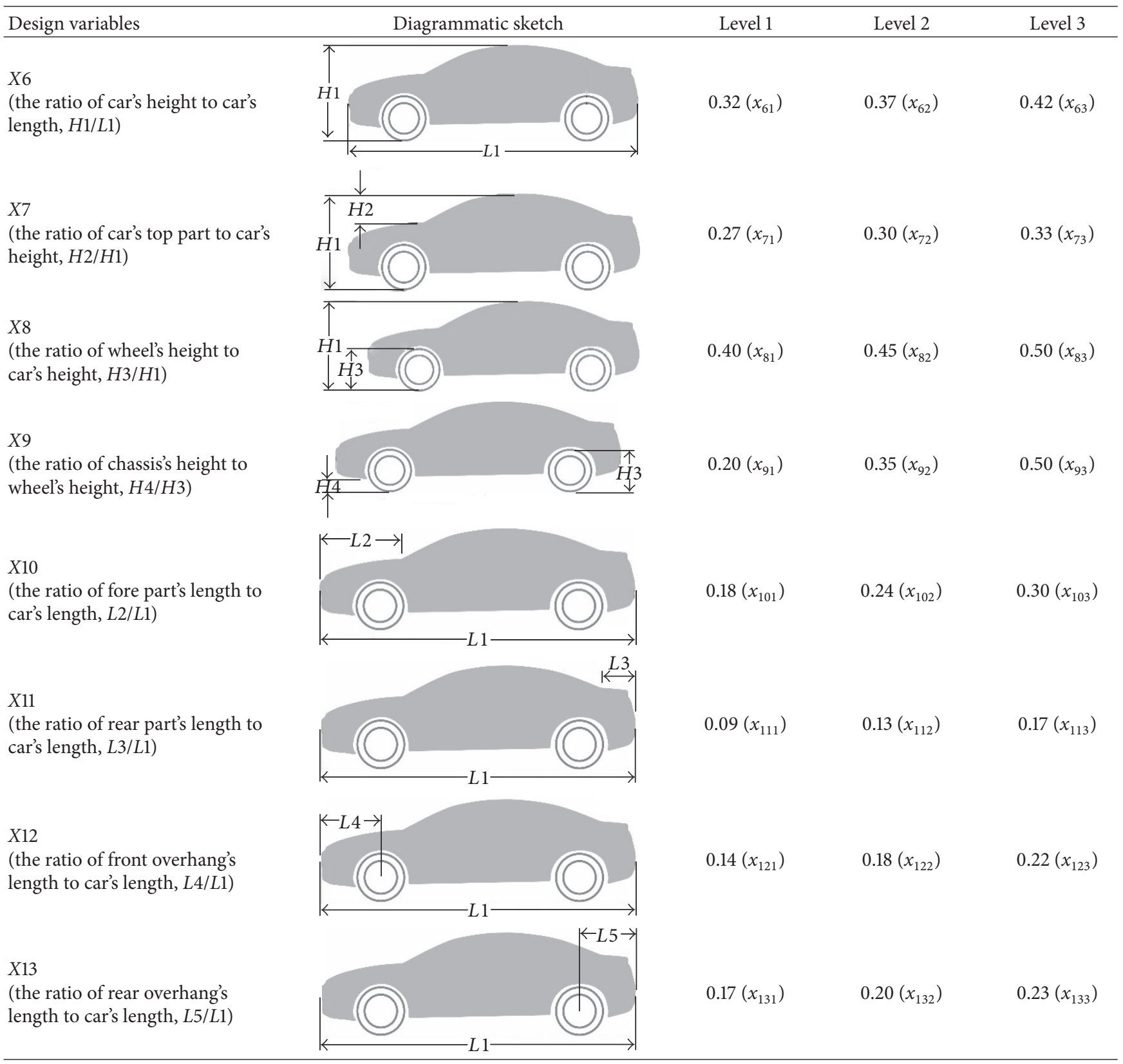

We applied the obtained experimental data to construct predictive models for affective responses using QT1; the affective response values for the four factors could thereby be predicted using the design variables, and the contribution of every design variable to affective response can also be obtained from the partial correlation coefficient. For example, the predictive model for "Traditional-Modern" is presented in Table 7. From this model, the affective response can be predicted, and it is clear that the car's height to length ratio (X6) is the most crucial design variable affecting "TraditionalModern," which has the highest partial correlation coefficient (0.468), followed by the shape of the top part (X3) and the ratio of rear part's length to the car's length $(X 11)$; the ratio of the rear overhang's length to the car's length $(X 13)$ is the least crucial design variable, which has the lowest partial correlation coefficient $(0.035)$.

For the semantic differential scale, to derive a design having a right-side affective response, it is necessary to maximize the scale; to derive a design having a left-side affective response, it is necessary to minimize the scale. In this study, it is assumed that the consumer requires a product which appears "Modern," "Comfortable," "Rounded," and "Simple," all of which are factors that lie on the right side of the semantic differential scale. Therefore, the MOO problem 
TABLE 5: Factor loadings of 20 pairwise adjectives using four factors.

\begin{tabular}{|c|c|c|c|c|}
\hline Pairwise adjectives & Factor 1 & Factor 2 & Factor 3 & Factor 4 \\
\hline Traditional-Modern & 0.956 & 0.108 & 0.096 & 0.032 \\
\hline Common-Exclusive & $\underline{0.946}$ & 0.257 & -0.048 & -0.022 \\
\hline Usual-High-tech & $\underline{0.938}$ & 0.293 & 0.065 & 0.037 \\
\hline Static-Dynamic & $\underline{0.920}$ & -0.034 & 0.143 & -0.001 \\
\hline Nostalgic-Avant-garde & $\underline{0.900}$ & 0.396 & 0.069 & 0.026 \\
\hline Straight-Streamlined & $\underline{0.862}$ & 0.308 & 0.196 & -0.121 \\
\hline Cheap-Expensive & $\underline{0.801}$ & 0.545 & -0.132 & -0.054 \\
\hline Calming-Exciting & $\underline{0.688}$ & 0.618 & 0.004 & 0.130 \\
\hline Dull-Vivid & 0.667 & -0.327 & 0.622 & 0.013 \\
\hline Coarse-Delicate & $\underline{0.656}$ & 0.652 & 0.264 & 0.128 \\
\hline Uncomfortable-Comfortable & 0.104 & $\underline{0.943}$ & -0.229 & 0.018 \\
\hline Awkward-Elegant & 0.404 & 0.902 & 0.063 & 0.069 \\
\hline Ugly-Beautiful & 0.417 & $\underline{0.874}$ & 0.083 & 0.121 \\
\hline Fragile-Strong & 0.224 & $\underline{0.854}$ & -0.333 & 0.253 \\
\hline Light-Heavy & -0.297 & $\underline{0.829}$ & -0.341 & 0.247 \\
\hline Plain-Luxurious & 0.619 & $\underline{0.766}$ & 0.074 & 0.030 \\
\hline Somber-Delightful & 0.614 & $\underline{0.723}$ & 0.245 & 0.118 \\
\hline Orthogonal-Rounded & 0.102 & -0.075 & $\underline{0.890}$ & 0.015 \\
\hline Complex-Simple & -0.060 & 0.127 & 0.309 & $\underline{0.837}$ \\
\hline Feminine-Masculine & 0.055 & 0.220 & -0.339 & $\underline{0.834}$ \\
\hline \multicolumn{5}{|l|}{ Final statistics } \\
\hline Eigenvalue & 8.340 & 6.690 & 1.911 & 1.609 \\
\hline Percentage of variance & 41.699 & 33.450 & 9.557 & 8.046 \\
\hline Cumulative percentage & 41.699 & 75.148 & 84.706 & 92.752 \\
\hline
\end{tabular}

The bold numbers indicate the groups of adjectives associated with factors 1-4.

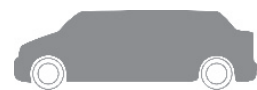

1
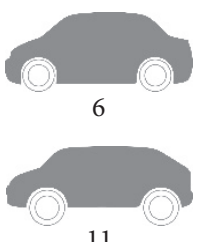

11
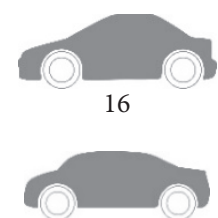

21

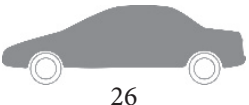

26

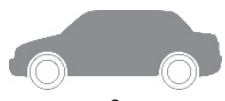

2

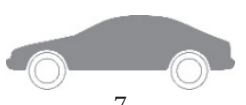

7
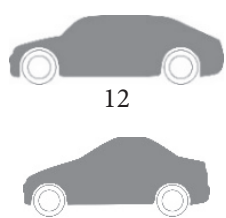

17

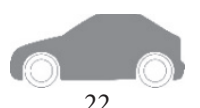

22

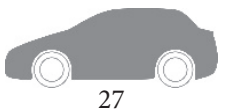

FIgURE 5: Twenty-seven combinative designs.
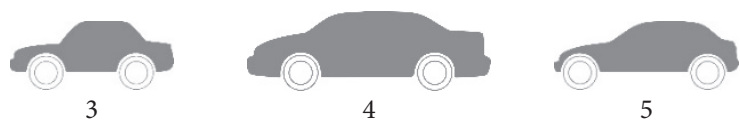

5
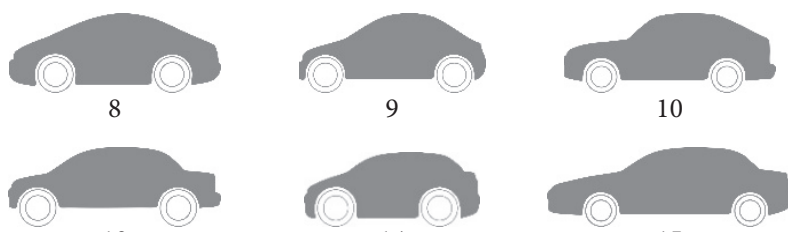

13
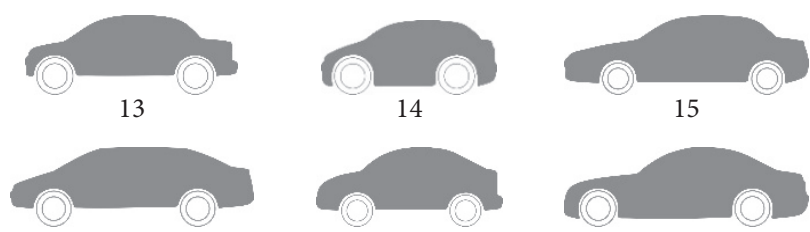

18

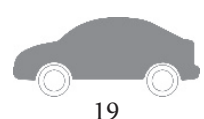

19

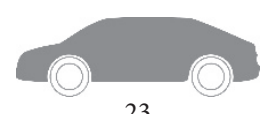

23

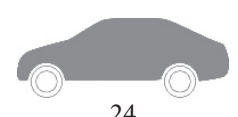

24
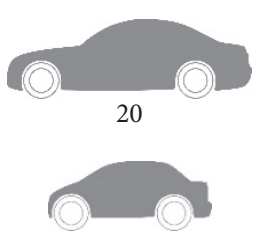

25 
TABLE 6: Evaluation matrix for 27 representative car samples.

\begin{tabular}{|c|c|c|c|c|c|}
\hline \multirow{2}{*}{ Sample number } & \multirow{2}{*}{$\begin{array}{c}\text { Design variables } \\
X 1-X 13 \\
\end{array}$} & \multicolumn{4}{|c|}{ Affective responses } \\
\hline & & Traditional-Modern & Uncomfortable-Comfortable & Orthogonal-Rounded & Complex-Simple \\
\hline 1 & 1111111111111 & 4.20 & 4.52 & 2.28 & 3.33 \\
\hline 2 & 1111222222222 & 3.88 & 4.07 & 2.87 & 3.40 \\
\hline 3 & 1111333333333 & 2.27 & 2.83 & 2.37 & 3.93 \\
\hline 4 & 1222111222333 & 4.57 & 4.20 & 3.53 & 3.67 \\
\hline 5 & 1222222333111 & 4.52 & 4.37 & 4.07 & 3.98 \\
\hline 6 & 1222333111222 & 2.95 & 4.12 & 4.93 & 3.87 \\
\hline 7 & 1333111333222 & 5.50 & 4.17 & 4.37 & 4.93 \\
\hline 8 & 1333222111333 & 4.62 & 3.97 & 5.62 & 4.90 \\
\hline 9 & 1333333222111 & 4.20 & 4.45 & 5.55 & 4.70 \\
\hline 10 & 2123123123123 & 4.85 & 4.68 & 3.93 & 4.17 \\
\hline 11 & 2123231231231 & 3.35 & 3.97 & 4.03 & 3.57 \\
\hline 12 & 2123312312312 & 4.45 & 4.37 & 3.97 & 4.28 \\
\hline 13 & 2231123231312 & 4.17 & 4.20 & 4.50 & 3.82 \\
\hline 14 & 2231231312123 & 3.07 & 4.03 & 5.22 & 3.28 \\
\hline 15 & 2231312123231 & 5.50 & 4.63 & 4.28 & 4.45 \\
\hline 16 & 2312123312231 & 3.65 & 3.77 & 2.22 & 3.37 \\
\hline 17 & 2312231123312 & 2.77 & 2.80 & 2.58 & 2.83 \\
\hline 18 & 2312312231123 & 4.53 & 3.78 & 3.17 & 4.15 \\
\hline 19 & 3132132132132 & 3.90 & 4.83 & 5.17 & 4.70 \\
\hline 20 & 3132213213213 & 5.88 & 5.00 & 5.12 & 4.92 \\
\hline 21 & 3132321321321 & 3.30 & 3.03 & 3.80 & 3.97 \\
\hline 22 & 3213132213321 & 2.95 & 3.58 & 2.85 & 3.93 \\
\hline 23 & 3213213321132 & 4.43 & 4.18 & 3.18 & 3.68 \\
\hline 24 & 3213321132213 & 4.45 & 4.15 & 3.67 & 4.73 \\
\hline 25 & 3321132321213 & 3.25 & 3.97 & 4.38 & 4.17 \\
\hline 26 & 3321213132321 & 5.10 & 4.07 & 3.55 & 4.77 \\
\hline 27 & 3321321213132 & 4.45 & 4.48 & 4.22 & 4.68 \\
\hline
\end{tabular}

is the maximization of the four scales and the MOO model can be presented as follows:

$$
\begin{array}{ll}
\text { Maximize } & y_{\text {Modern }}=\sum_{i=1}^{13} \sum_{j=1}^{3} \beta_{i j 1} x_{i j}+\varepsilon_{1}, \\
\text { Maximize } & y_{\text {Comfortable }}=\sum_{i=1}^{13} \sum_{j=1}^{3} \beta_{i j 2} x_{i j}+\varepsilon_{2}, \\
\text { Maximize } & y_{\text {Rounded }}=\sum_{i=1}^{13} \sum_{j=1}^{3} \beta_{i j 3} x_{i j}+\varepsilon_{3}, \\
\text { Maximize } & y_{\text {Simple }}=\sum_{i=1}^{13} \sum_{j=1}^{3} \beta_{i j 4} x_{i j}+\varepsilon_{4}, \\
\text { Subject to } & x_{i j}=\{0,1\}, \\
& \sum_{j=1}^{3} x_{i j}=1 .
\end{array}
$$

4.2. Pareto Optimal Solutions Generation. NSGA-II was employed to solve the MOO model. Simulated binary crossover (SBX) and polynomial mutation were adopted in
NSGA-II. The SBX and polynomial mutation are widely used in MOEA research [25]. The tuned parameters for optimization were specified as follows: 25,000 evaluations; a population size of 100; a distribution index of 15 for SBX; a crossover rate of 0.8 ; a distribution index of 20 for mutation; and a mutation rate of $1 / n$, where $n$ indicates the number of variables. A total of 100 Pareto solutions were obtained, as shown in Table 8. The Pareto optimal frontier in objectives' space is illustrated in Figure 6.

4.3. Best Solution Selection. In this study, we used FAHP to determine the best design solution. The computational procedure is as follows.

Step 1. Assume that a consumer requires a car and has affective preferences that are expressed using pairwise comparisons, as shown in Table 9.

On the basis of the pairwise comparison, the fuzzy comparison matrix can be obtained as follows:

$$
\widetilde{A}=\left[\begin{array}{cccc}
1 & \widetilde{3} & \widetilde{7} & \widetilde{5} \\
\widetilde{3}^{-1} & 1 & \widetilde{5} & \widetilde{3} \\
\widetilde{7}^{-1} & \widetilde{5}^{-1} & 1 & \widetilde{3}^{-1} \\
\widetilde{5}^{-1} & \widetilde{3}^{-1} & \widetilde{3} & 1
\end{array}\right] .
$$




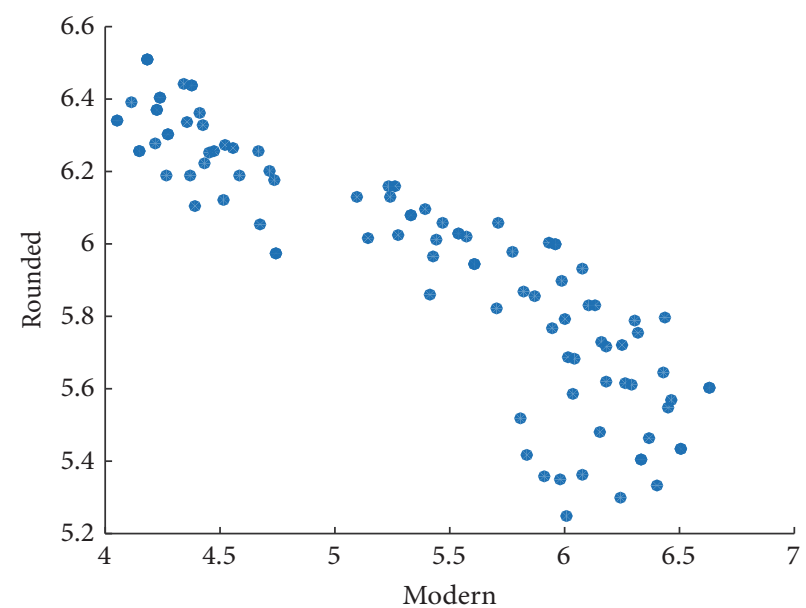

(a)

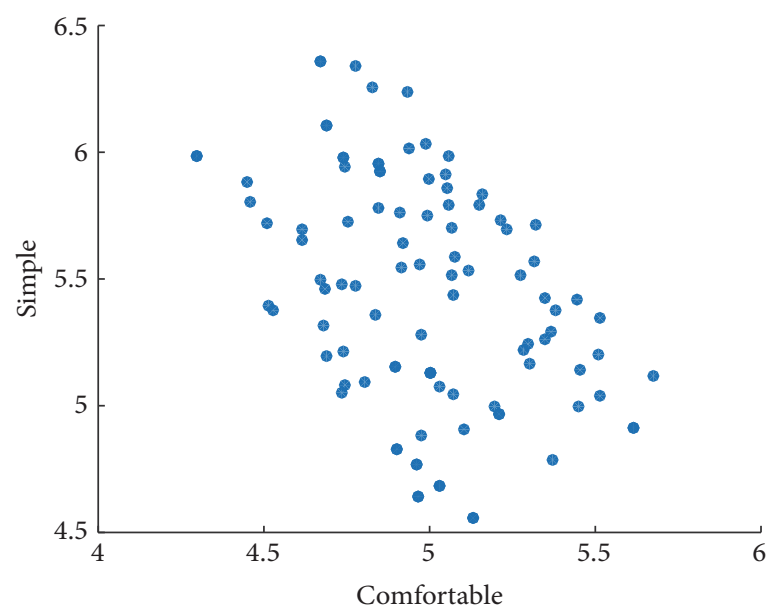

(b)

Figure 6: Pareto optimal frontier in objectives' space for (a) "Modern" and "Rounded" and (b) “Comfortable" and "Simple."

TABle 7: Predictive model for “Traditional-Modern” by using QT1.

\begin{tabular}{|c|c|c|c|}
\hline Design variables & Partial correlation coefficient & Levels & $\beta_{i j}$ \\
\hline \multirow{3}{*}{$X 1$} & \multirow{3}{*}{0.049} & 1 & -0.024 \\
\hline & & 2 & -0.065 \\
\hline & & 3 & 0.089 \\
\hline \multirow{3}{*}{$X 2$} & \multirow{3}{*}{0.070} & 1 & -0.093 \\
\hline & & 2 & -0.035 \\
\hline & & 3 & 0.128 \\
\hline \multirow{3}{*}{$X 3$} & \multirow{3}{*}{0.234} & 1 & -0.420 \\
\hline & & 2 & 0.063 \\
\hline & & 3 & 0.357 \\
\hline \multirow{3}{*}{$X 4$} & \multirow{3}{*}{0.110} & 1 & -0.115 \\
\hline & & 2 & -0.094 \\
\hline & & 3 & 0.209 \\
\hline \multirow{3}{*}{$X 5$} & \multirow{3}{*}{0.052} & 1 & 0.013 \\
\hline & & 2 & 0.078 \\
\hline & & 3 & -0.091 \\
\hline \multirow{3}{*}{$X 6$} & \multirow{3}{*}{0.468} & 1 & 0.806 \\
\hline & & 2 & 0.107 \\
\hline & & 3 & -0.913 \\
\hline \multirow{3}{*}{$X 7$} & \multirow{3}{*}{0.074} & 1 & -0.141 \\
\hline & & 2 & 0.076 \\
\hline & & 3 & 0.065 \\
\hline \multirow{3}{*}{$X 8$} & \multirow{3}{*}{0.145} & 1 & 0.157 \\
\hline & & 2 & 0.119 \\
\hline & & 3 & -0.276 \\
\hline \multirow{3}{*}{$X 9$} & \multirow{3}{*}{0.054} & 1 & -0.078 \\
\hline & & 2 & -0.019 \\
\hline & & 3 & 0.096 \\
\hline \multirow{3}{*}{$X 10$} & \multirow{3}{*}{0.132} & 1 & -0.235 \\
\hline & & 2 & 0.039 \\
\hline & & 3 & 0.196 \\
\hline \multirow{3}{*}{$X 11$} & \multirow{3}{*}{0.159} & 1 & 0.137 \\
\hline & & 2 & 0.167 \\
\hline & & 3 & -0.304 \\
\hline
\end{tabular}

TABLE 7: Continued.

\begin{tabular}{lccc}
\hline Design variables & Partial correlation coefficient & Levels & $\beta_{i j}$ \\
\hline \multirow{2}{*}{ X12 } & 0.060 & 1 & 0.107 \\
& & 2 & -0.087 \\
& & 3 & -0.020 \\
\hline \multirow{2}{*}{ X13 } & \multirow{2}{*}{0.035} & 1 & -0.017 \\
& & 2 & -0.046 \\
& & 3 & 0.063 \\
\hline
\end{tabular}

Step 2. For a moderate decision-maker, set $\alpha=0.8$ and $\mu=$ 0.5 [39]. Combining (7), (8), (9), (10), and (11), $\widehat{A}_{0.8}$ can be derived as follows:

$$
\widehat{A}_{0.8}=\left[\begin{array}{llll}
1.000 & 3.000 & 7.000 & 5.000 \\
0.339 & 1.000 & 5.000 & 3.000 \\
0.143 & 0.201 & 1.000 & 0.339 \\
0.201 & 0.339 & 3.000 & 1.000
\end{array}\right] \text {. }
$$

Substituting $\widehat{A}_{0.8}$ into (12) yields the highest eigenvalue $\lambda_{\max }=4.131$. Substituting $\lambda_{\max }$ into (13) provides the corresponding eigenvectors. Having been normalized, the importance weights of the affective responses can be determined as follows:

$$
W=[0.564,0.263,0.056,0.118]^{T}
$$

Step 3. In conducting the conformance test, we can derive that the C.I. is 0.044 and the C.R. is 0.049 by using (14). Because the values of C.I. and C.R. are both less than 0.10 , we can conclude that the consistency of the judgement matrix is satisfied. 
TABLE 8: One hundred Pareto solutions obtained by using NSGA-II.

\begin{tabular}{|c|c|c|c|c|c|}
\hline \multirow{2}{*}{ Sample number } & \multirow{2}{*}{$\begin{array}{c}\text { Design variables } \\
X 1-X 13\end{array}$} & \multicolumn{4}{|c|}{ Affective responses } \\
\hline & & Modern & Comfortable & Rounded & Simple \\
\hline 1 & 3333332133213 & 4.74 & 4.30 & 5.97 & 5.98 \\
\hline 2 & 3233232212112 & 4.24 & 5.13 & 6.40 & 4.56 \\
\hline 3 & 3233332212113 & 4.18 & 5.00 & 6.51 & 5.13 \\
\hline$\vdots$ & $\vdots$ & $\vdots$ & $\vdots$ & $\vdots$ & $\vdots$ \\
\hline 100 & 3333212133233 & 6.50 & 4.74 & 5.44 & 5.98 \\
\hline
\end{tabular}

TABlE 9: Pairwise comparison of affective responses.

\begin{tabular}{|c|c|c|c|c|c|c|c|c|c|c|c|}
\hline Affective responses & $\begin{array}{c}\text { EXI } \\
\widetilde{9}\end{array}$ & $\begin{array}{c}\text { VSI } \\
\widetilde{7}\end{array}$ & $\begin{array}{c}\text { SI } \\
\widetilde{5}\end{array}$ & $\begin{array}{c}\mathrm{MI} \\
\widetilde{3}\end{array}$ & $\begin{array}{c}\text { EI } \\
\widetilde{1} \\
\end{array}$ & $\begin{array}{c}\text { EI } \\
\tilde{1}^{-1} \\
\end{array}$ & $\begin{array}{l}\mathrm{MI} \\
\widetilde{3}^{-1}\end{array}$ & $\begin{array}{c}\text { SI } \\
\widetilde{5}^{-1}\end{array}$ & $\begin{array}{l}\text { VSI } \\
\widetilde{7}^{-1}\end{array}$ & $\begin{array}{c}\text { EXI } \\
\widetilde{9}^{-1}\end{array}$ & Affective responses \\
\hline Modern & & & & $\sqrt{ }$ & & & & & & & Comfortable \\
\hline Modern & & $\sqrt{ }$ & & & & & & & & & Rounded \\
\hline Modern & & & $\sqrt{ }$ & & & & & & & & Simple \\
\hline Comfortable & & & $\sqrt{ }$ & & & & & & & & Rounded \\
\hline Comfortable & & & & $\sqrt{ }$ & & & & & & & Simple \\
\hline Rounded & & & & & & & $\sqrt{ }$ & & & & Simple \\
\hline
\end{tabular}

TABle 10: Typical design solutions in the ranking of Pareto set.

\begin{tabular}{|c|c|c|c|c|c|c|c|c|}
\hline Ranking & $\begin{array}{l}\text { Solution } \\
\text { number }\end{array}$ & $\begin{array}{l}\text { Design variables } \\
\quad(X 1-X 13)\end{array}$ & Modern & $\begin{array}{l}\text { Affective res } \\
\text { Comfortable }\end{array}$ & $\begin{array}{l}\text { sponses } \\
\text { Rounded }\end{array}$ & Simple & Performance value & Design sketches \\
\hline 1 & 37 & 3333212133213 & 6.63 & 4.84 & 5.60 & 5.96 & 6.03 & \\
\hline 63 & 27 & 3233322112233 & 5.14 & 4.97 & 6.01 & 5.56 & 5.19 & \\
\hline 64 & 2 & 3333332133213 & 4.74 & 4.30 & 5.97 & 5.98 & 4.84 & \\
\hline 100 & 98 & 3233332212133 & 4.05 & 4.89 & 6.34 & 5.15 & 4.53 & \\
\hline
\end{tabular}

Step 4. On the basis of Table 8, the decision matrix $C$ for the four affective responses and the 100 alternatives can be calculated as follows:

$$
C=\left[\begin{array}{cccc}
4.74 & 4.30 & 5.97 & 5.98 \\
4.24 & 5.13 & 6.40 & 4.56 \\
4.18 & 5.00 & 6.51 & 5.13 \\
\vdots & \vdots & \vdots & \vdots \\
6.50 & 4.74 & 5.44 & 5.98
\end{array}\right]
$$

According to the importance weights of the affective responses, we can compute the performance value matrix $V$ by using (16) as follows:

$$
V=\left[\begin{array}{lllll}
4.841 & 4.633 & 4.638 & \cdots & 5.919
\end{array}\right]^{T} .
$$

Rank the design alternatives by the performance values as Solution number $37>$ Solution number 1

$$
\begin{aligned}
& >\text { Solution number } 13>\cdots \\
& >\text { Solution number } 98 .
\end{aligned}
$$

The ranking of the Pareto solutions is depicted in Figure 7. Solution number 37 ranks 1st. Consequently, we can conclude that the optimal product form design solution is solution number 37.

4.4. Verification Result. To verify the result, typical design solutions were selected which corresponded to the indicative points in the ranking shown in Figure 7, such as the starting point, the end point, and the jumping points. The design variables, affective responses, and design sketches of these solutions are shown in Table 10. 
TABLE 11: Statistical scores for typical Pareto optimal solutions.

\begin{tabular}{lcccc}
\hline & Solution number 2 & Solution number 27 & Solution number 37 & Solution number 98 \\
\hline Modern & 4.81 & 5.10 & 6.65 & 4.10 \\
Comfortable & 4.41 & 4.93 & 4.81 & 4.85 \\
Rounded & 5.93 & 6.04 & 5.62 & 6.38 \\
Simple & 6.01 & 5.55 & 6.00 & 5.20 \\
Performance value & 4.91 & 5.17 & 6.04 & 4.56 \\
Ranking & 3 & 2 & 1 & 4 \\
\hline
\end{tabular}

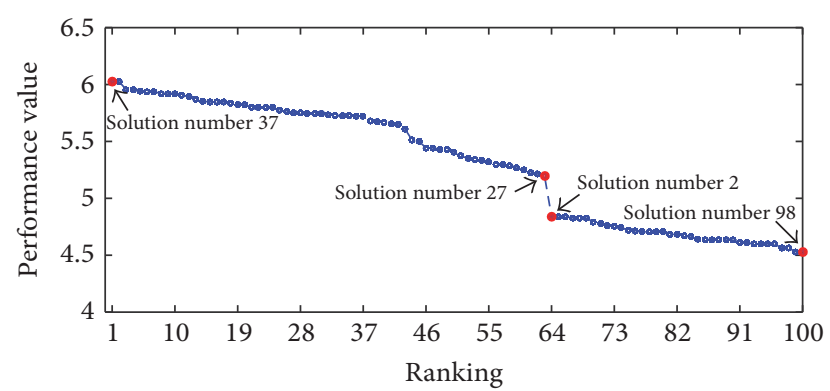

Figure 7: Ranking of 100 Pareto solutions.

We combined the design sketches with the four affective responses to construct the questionnaire, which was filled in by a total of 60 respondents. The statistical scores are shown in Table 11, where the performance values were calculated according to the importance weights. It is evident that solution number $37>$ solution number $27>$ solution number $2>$ solution number 98 ; this sequence indicates that the results of the evaluation for the Pareto set are the same as the statistics of the affective responses of actual respondents. Therefore, this method can be used by designers to derive various Pareto optimal design solutions corresponding to consumers' multiple affective responses and can also obtain the optimal design solution on the basis of consumers' preference weights for these responses.

\section{Discussion}

This paper proposes an integrated product form design method in which the MOO process is applied to obtain a Pareto set, and then the MCDM process is performed to derive the optimal design according to the preference weights. The MOO is a type of search process and the MCDM is a type of decision-making process. To obtain an optimal design solution, the search process and the decision process need to be integrated. In the proposed product form design model, the decision process is posterior to the search process; hence, it can be categorised as a posterior preference articulation approach [9]. The decisionmaker directly applies higher-level information related to affective preference to a set of preestablished Pareto optimal designs and thus enables clearer insight into design decisions. By contrast, for a traditional prior preference articulation approach which transforms MOO into SOO, the decisionmaker must quantify opinions before viewing the potential design solutions. Therefore, the final solution with the posterior preference articulation approach can reflect the decisionmaker's preference more accurately [40]. Furthermore, this design method is particularly useful in cases where the user has no prior knowledge through which to ascertain the preference weights for MARs [41].

In this integrated design model, when the user wants to change the importance weights for multiple affective responses, the optimal design can be chosen from the already obtained Pareto set merely by executing the decision-making process; the search process, which generally consumes considerable time by using GA $[4,5]$, does not require execution. Thus, the proposed model is more convenient and efficient.

We use QT1 to construct the predictive models for affective responses, on the basis of which the MOO model is established and the Pareto solutions are then obtained. QT1 provides an indication of the influence of various design variables on affective responses through the partial correlation coefficients, thereby facilitating the identification of crucial design variables. Nevertheless, the prediction accuracy tends to be low. If a more accurate predictive model is required, BPNN [5] or SVR [42] can be adopted. In addition, there are only 27 representative samples used in the experiment for prediction. The prediction reliability may be low because of the small sample size. Thus, more representative samples could be added to improve the prediction reliability.

The execution of the proposed method is demonstrated using a case study involving the design of a car profile. It should be mentioned that the design variables and corresponding levels can be changed according to the cars available on the market and the research focus. This approach can be applied to other products with various design elements, in which case design analysis should be performed to ascertain both the design variables and affective responses. Subsequently, the MOO and the MCDM can be executed using NSGA-II and FAHP, respectively.

\section{Conclusion}

Product form design has been recognized to contribute critically to a corporation's performance in the highly competitive contemporary global market. This paper has presented an integrated product form design model based on $\mathrm{MOO}$ and MCDM. The car profile design was used to illustrate the methodology, and the Pareto solution set satisfying MARs was derived and the optimal design solution most corresponding to the preference of consumer was then obtained. 
The results indicate that the proposed product form design model can address multiple objectives for MARs simultaneously and ensure that the design decision process is less subjective and more practical. Furthermore, this approach can provide great insight for design and is particularly helpful for users without prior knowledge in specifying the relative importance of criteria.

It should be noted that in this study all possible product form designs are generated from the combination of the defined design variables. Therefore, the obtained new forms are always from the known specified patterns. How to develop a new form design different from the collected forms is important for the realistic design. Further research would focus on this topic. In addition, there are many types of MOO methods, for example, NSGA-II, PESA-II, and SPEA2, as well as many types of MCDM methods, for example, AHP, FAHP, and TOPSIS. In the future, comparison studies could be carried out to make sure which type of MOO or MCDM method is most suitable in the context of Kansei engineering.

\section{Competing Interests}

The authors declare that there are no competing interests regarding the publication of this paper.

\section{Acknowledgments}

This work was supported by the Ministry of Science and Technology, Taiwan (Project no. MOST 102-2221-E-006-213). The authors would like to express their sincere thanks to the participants for their assistance in this study.

\section{References}

[1] M. Nagamachi, Kansei/Affective Engineering, CRC Press, Boca Raton, Fla, USA, 2010.

[2] K.-C. Wang and F.-R. Ju, "An innovative design methodology KKBDCA for affective product development," Mathematical Problems in Engineering, vol. 2013, Article ID 629708, 10 pages, 2013.

[3] C. Kittidecha and A. C. Marasinghe, "Application of Kansei Engineering and Box-Behnken response surface methodology for shape parameter design: a case study of wine glass," Journal of Advanced Mechanical Design, Systems, and Manufacturing, vol. 9, no. 5, pp. 1-12, 2015.

[4] S.-W. Hsiao, F.-Y. Chiu, and S.-H. Lu, "Product-form design model based on genetic algorithms," International Journal of Industrial Ergonomics, vol. 40, no. 3, pp. 237-246, 2010.

[5] F. Guo, W. L. Liu, F. T. Liu, H. Wang, and T. B. Wang, "Emotional design method of product presented in multi-dimensional variables based on Kansei Engineering," Journal of Engineering Design, vol. 25, no. 4-6, pp. 194-212, 2014.

[6] K. Deb, Multi-Objective Optimization Using Evolutionary Algorithms, John Wiley \& Sons, West Sussex, UK, 2001.

[7] M. H. Ahmadi, M. A. Ahmadi, R. Bayat, M. Ashouri, and M. Feidt, "Thermo-economic optimization of Stirling heat pump by using non-dominated sorting genetic algorithm," Energy Conversion and Management, vol. 91, pp. 315-322, 2015.
[8] N. Padhye and K. Deb, "Multi-objective optimisation and multicriteria decision making in SLS using evolutionary approaches," Rapid Prototyping Journal, vol. 17, no. 6, pp. 458-478, 2011.

[9] D.-H. Lee, K.-J. Kim, and M. Köksalan, "A posterior preference articulation approach to multiresponse surface optimization," European Journal of Operational Research, vol. 210, no. 2, pp. 301-309, 2011.

[10] J. Branke, MCDA and Multiobjective Evolutionary Algorithms, Springer, New York, NY, USA, 2016.

[11] L. T. Bui and S. Alam, Multi-Objective Optimization in Computational Intelligence: Theory and Practice, IGI Global, Hershey, Pa, USA, 2008.

[12] C.-C. Yang, "Constructing a hybrid Kansei engineering system based on multiple affective responses: application to product form design," Computers \& Industrial Engineering, vol. 60, no. 4, pp. 760-768, 2011.

[13] H. Jiang, C. K. Kwong, Y. Liu, and W. H. Ip, "A methodology of integrating affective design with defining engineering specifications for product design," International Journal of Production Research, vol. 53, no. 8, pp. 2472-2488, 2015.

[14] M. Nagamachi, "Kansei engineering as a powerful consumeroriented technology for product development," Applied Ergonomics, vol. 33, no. 3, pp. 289-294, 2002.

[15] Y. Matsubara and M. Nagamachi, "Hybrid Kansei engineering system and design support," International Journal of Industrial Ergonomics, vol. 19, no. 2, pp. 81-92, 1997.

[16] E. Tjalve, A Short Course in Industrial Design, NewnesButterworths, London, UK, 1979.

[17] K. H. Hyun, J.-H. Lee, M. Kim, and S. Cho, "Style synthesis and analysis of car designs for style quantification based on product appearance similarities," Advanced Engineering Informatics, vol. 29, no. 3, pp. 483-494, 2015.

[18] H. C. Yadav, R. Jain, A. R. Singh, and P. K. Mishra, "Aesthetical design of a car profile: a Kano model-based hybrid approach," The International Journal of Advanced Manufacturing Technology, vol. 67, no. 9-12, pp. 2137-2155, 2013.

[19] H.-H. Lai, Y.-M. Chang, and H.-C. Chang, "A robust design approach for enhancing the feeling quality of a product: a car profile case study," International Journal of Industrial Ergonomics, vol. 35, no. 5, pp. 445-460, 2005.

[20] F. Cluzel, B. Yannou, and M. Dihlmann, "Using evolutionary design to interactively sketch car silhouettes and stimulate designer's creativity," Engineering Applications of Artificial Intelligence, vol. 25, no. 7, pp. 1413-1424, 2012.

[21] H.-Y. Chen, Y.-M. Chang, and T.-C. Tung, "Comparison of two quantitative analysis techniques to predict the evaluation of product form design," Mathematical Problems in Engineering, vol. 2014, Article ID 989382, 9 pages, 2014.

[22] H.-C. Tsai, S.-W. Hsiao, and F.-K. Hung, "An image evaluation approach for parameter-based product form and color design," Computer-Aided Design, vol. 38, no. 2, pp. 157-171, 2006.

[23] S. Toghyani, A. Kasaeian, S. H. Hashemabadi, and M. Salimi, "Multi-objective optimization of GPU3 Stirling engine using third order analysis," Energy Conversion and Management, vol. 87, pp. 521-529, 2014.

[24] C. A. Coello Coello, G. B. Lamont, and D. A. Van Veldhuizen, Evolutionary Algorithms for Solving Multi-Objective Problems, Springer, New York, NY, USA, 2nd edition, 2007.

[25] C. Igel, N. Hansen, and S. Roth, "Covariance matrix adaptation for multi-objective optimization," Evolutionary Computation, vol. 15, no. 1, pp. 1-28, 2007. 
[26] N. Srinivas and K. Deb, "Muiltiobjective optimization using nondominated sorting in genetic algorithms," Evolutionary Computation, vol. 2, no. 3, pp. 221-248, 1994.

[27] K. Deb, A. Pratap, S. Agarwal, and T. Meyarivan, "A fast and elitist multiobjective genetic algorithm: NSGA-II," IEEE Transactions on Evolutionary Computation, vol. 6, no. 2, pp. 182197, 2002.

[28] G.-H. Tzeng and J.-J. Huang, Multiple attribute decision making: methods and applications, CRC Press, Boca Raton, Fla, USA, 2011.

[29] T. L. Saaty, The Analytic Hierarchy Process: Planning, Priority Setting, Resources Allocation, McGraw-Hill, New York, NY, USA, 1980.

[30] P. J. van Laarhoven and W. Pedrycz, "The use of parametric programming in fuzzy linear programming," Fuzzy Sets and Systems, vol. 11, no. 1-3, pp. 243-251, 1983.

[31] J. J. Buckley, "Fuzzy hierarchical analysis," Fuzzy Sets and Systems, vol. 17, no. 3, pp. 233-247, 1985.

[32] N. Cross, Engineering Design Methods: Stragies for Prouduct Design, John Wiley \& Sons, Chichester, UK, 4th edition, 2008.

[33] S.-W. Hsiao and C.-H. Chen, "A semantic and shape grammar based approach for product design," Design Studies, vol. 18, no. 3, pp. 275-296, 1997.

[34] G. Klir and B. Yuan, Fuzzy Sets and Fuzzy Logic, Prentice Hall, New Jersey, NJ, USA, 1995.

[35] C. K. Kwong and H. Bai, "A fuzzy AHP approach to the determination of importance weights of customer requirements in quality function deployment," Journal of Intelligent Manufacturing, vol. 13, no. 5, pp. 367-377, 2002.

[36] C.-H. Yeh, H. Deng, and Y.-H. Chang, "Fuzzy multicriteria analysis for performance evaluation of bus companies," European Journal of Operational Research, vol. 126, no. 3, pp. 459-473, 2000.

[37] A. R. Lee, Application of Modified Fuzzy AHP Method to Analyze Bolting Sequence of Structural Joints, Lehigh University, Bethlehem, Pa, USA, 1995.

[38] S.-W. Hsiao and Y.-C. Ko, "A study on bicycle appearance preference by using FCE and FAHP," International Journal of Industrial Ergonomics, vol. 43, no. 4, pp. 264-273, 2013.

[39] C. Kahraman, Fuzzy Multi-Criteria Decision Making: Theory and Applications with Recent Developments, Springer Science \& Business Media, New York, NY, USA, 2008.

[40] R. T. Marler and J. S. Arora, "Survey of multi-objective optimization methods for engineering," Structural and Multidisciplinary Optimization, vol. 26, no. 6, pp. 369-395, 2004.

[41] M. Camargo, L. Wendling, and E. Bonjour, "A fuzzy integral based methodology to elicit semantic spaces in usability tests," International Journal of Industrial Ergonomics, vol. 44, no. 1, pp. 11-17, 2014.

[42] K.-C. Wang, "A hybrid Kansei engineering design expert system based on grey system theory and support vector regression," Expert Systems with Applications, vol. 38, no. 7, pp. 8738-8750, 2011. 


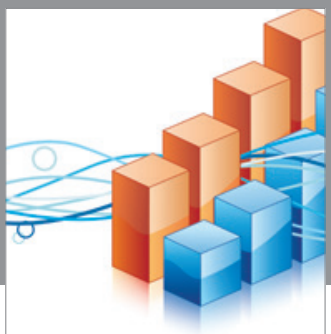

Advances in

Operations Research

vatem alat4

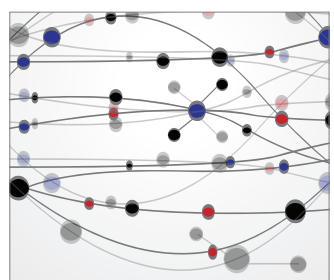

\section{The Scientific} World Journal
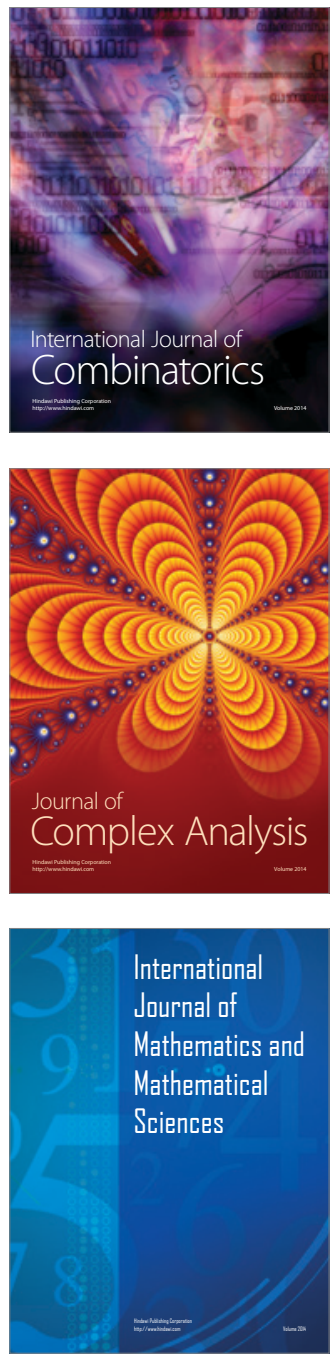
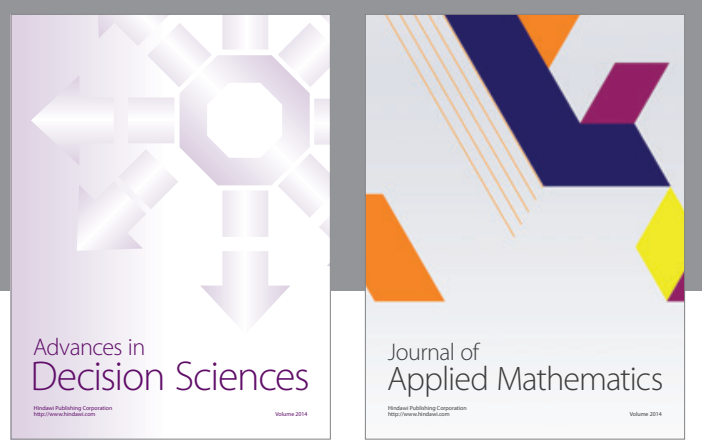

Algebra

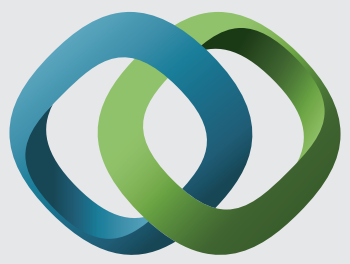

\section{Hindawi}

Submit your manuscripts at

https://www.hindawi.com
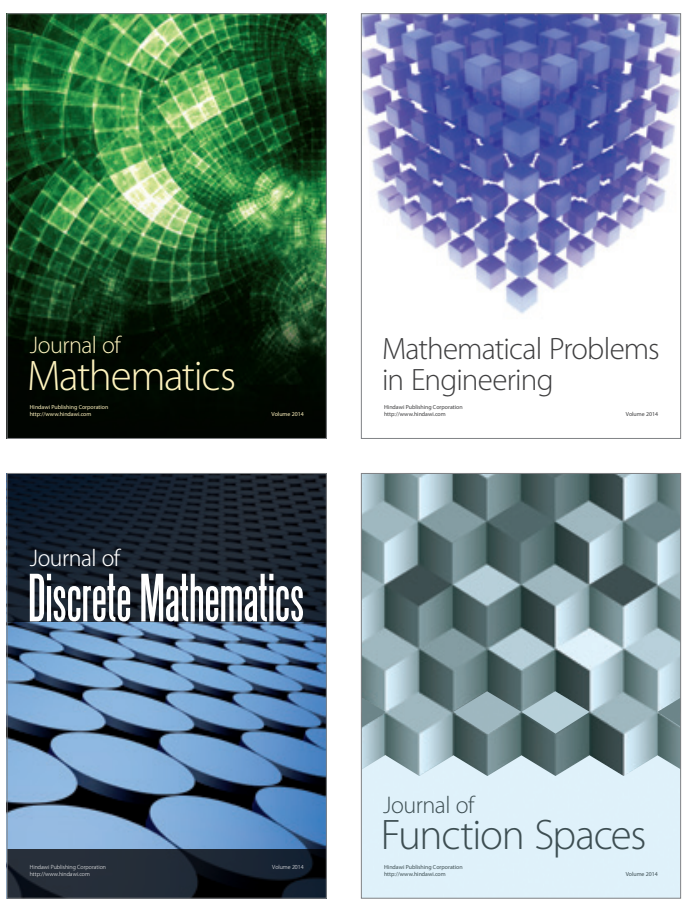

Mathematical Problems in Engineering
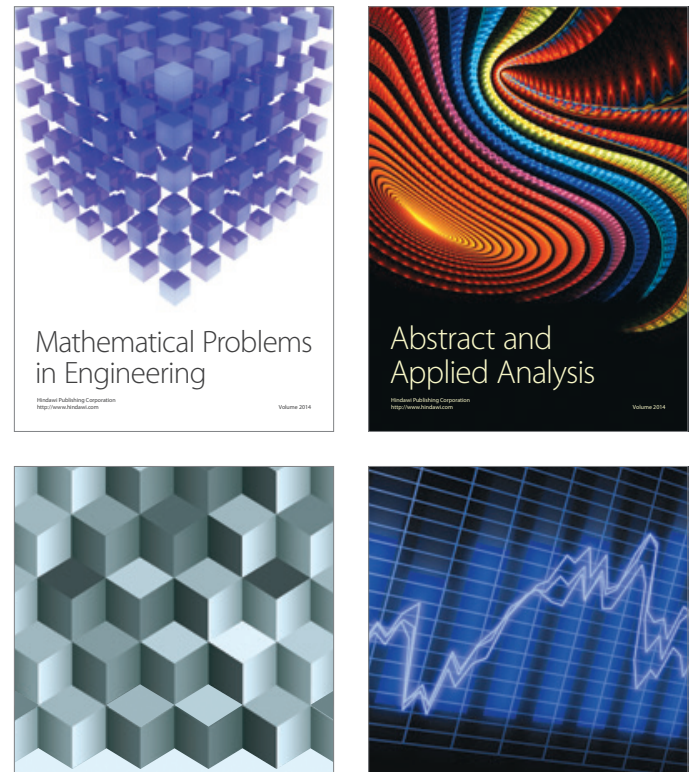

Journal of

Function Spaces

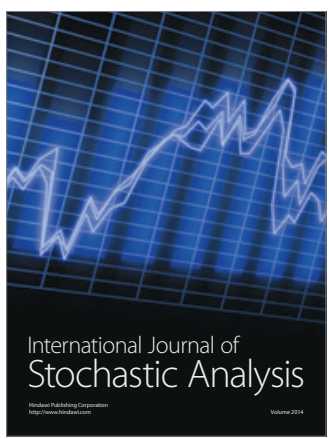

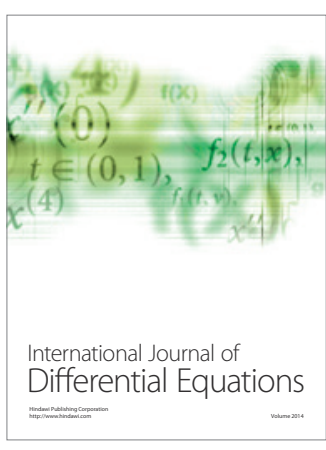
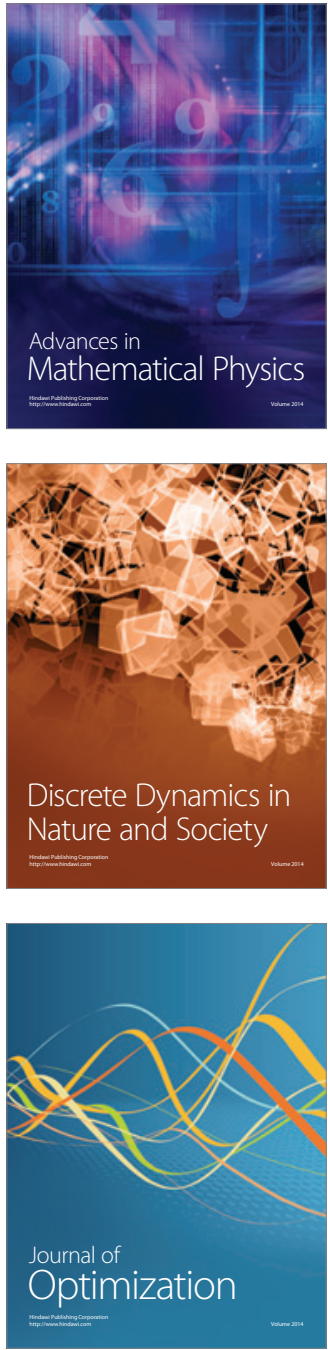